\title{
Cryptic species in sympatry: nonrandom small-scale distribution patterns in Bostrychia intricata (Ceramiales, Rhodophyta)
}

\author{
Narongrit Muangmai ${ }^{1 *}$, Ulla von Ammon ${ }^{2}$ and Giuseppe C. Zuccarello ${ }^{1}$ \\ ${ }^{1}$ School of Biological Sciences, Victoria University of Wellington, Wellington, 6041 New Zealand \\ ${ }^{2}$ School of Biological Sciences, The University of Auckland, Auckland, 1142 New Zealand
}

\begin{abstract}
AвSTRACT: Sympatric coexistence of cryptic species, indistinguishable morphological taxa, has increasingly been detected on the basis of molecular data. This discovery raises the interesting question of how cryptic species can coexist, as hypothetically they would need identical ecological resources. The red alga Bostrychia intricata is commonly found along New Zealand shores. Previous studies indicated several cryptic species within this morphospecies, and that some populations have multiple species. This study aimed to determine how coexisting cryptic $B$. intricata distribute at a small scale. Along the shore of Moa Point, Wellington, we conducted intensive sampling of $B$. intricata in different habitats with respect to tidal position, wave and sun exposure levels. Our genetic data clearly documented the coexistence of three cryptic species of B. intricata: N2, N4 and N5. Multiple samples from individual algal patches indicated that each patch was made of the same ramet. Our analyses revealed a habitat-related pattern in small-scale distribution of different cryptic $B$. intricata, suggesting that the distribution of these cryptic species was not random. Cryptic species N4 was found at a higher tidal position than species $\mathrm{N} 2$ and N5, whereas cryptic species $\mathrm{N} 2$ occurred in more wave-exposed areas than the other species. Discriminant analysis indicated that tidal height strongly influenced the distribution pattern among these cryptic species. Our observations demonstrated that the co-occurrence of three cryptic B. intricata can partly be explained by their occupation of different intertidal habitats, highlighting the nonrandom distribution of coexisting cryptic algal species.
\end{abstract}

Key Words: Coexistence, Cytochrome oxidase subunit 1, Habitat, Macroalgae, Physical factors, Rhodomelaceae, Rhodophyta, Tidal height

\section{INTRODUCTION}

Mechanisms that maintain the coexistence of multiple species in sympatry are likely the most challenging topic in community ecology (Lankau 2011). Several studies in animal and plant communities have revealed that in the same area, competing species can stably coexist by occupying different niches (Tokeshi 1999; Silvertown 2004; Zhang et al. 2004). The niche is often defined as a specific resource, behavior or environmental circumstance of one species, which is generally influenced by biotic and abiotic factors such as interand intraspecific interactions, gradients of light and temperature or seawater chemistry (Odum 1959; Silvertown 2004; Levinton 2013). In intertidal ecosystems, many studies have previously demonstrated temporal and spatial niche differentiations (e.g. reproductive timing, tidal position and exposure level) among competing taxa, allowing them to coexist at small scales (Benzie et al. 2000; De Troch et al. 2003; Sampayo et al. 2007; Tronholm et al. 2010; Lai et al. 2011; Zardi et al. 2011). For example, within mid-intertidal pools along the northern Gulf of California, the brown alga Sargassum johnstonii Setchell \& Gardner grew at a shallower depth than S. sinicola subsp. camouii (Dawson) Norris \& Yensen (McCourt 1984).

Recently, molecular data have been used to solve taxonomic problems in marine species and uncover hidden diversity (Knowlton 2000; Zuccarello \& West 2003, 2006;

* Corresponding author (seaweed_53@hotmail.com).

DOI: $10.2216 / 16-5.1$

(C) 2016 International Phycological Society
Lindstrom 2008; Tronholm et al. 2010). Cryptic species are a group of two or more morphologically indistinguishable species (Bickford et al. 2007). In marine red algae, the incidence of cryptic species is relatively common (Zuccarello et al. 2002; Zuccarello \& West 2003; Payo et al. 2013; Muangmai et al. 2014). Although morphologically indistinguishable, cryptic red algal species can be distinctly different in other aspects of their biology, e.g. distribution patterns, mating systems and physiological performance (Kamiya et al. 1998; Zuccarello \& West 2003; Kamiya \& West 2014; Muangmai et al. 2014, 2015a).

The discovery of the coexistence of cryptic algal species has also become significantly frequent (Zuccarello \& West 2003; Fraser et al. 2013; Muangmai et al. 2015a). According to the competitive exclusion principle proposed by Gause (1934), the shared morphology of cryptic algal species would suggest that they need similar, or even identical, ecological resources and would compete with each other. Therefore, the species that has a competitive advantage would eliminate its competitors from the area, and coexistence would be unlikely. Recently, several studies have shown that cryptic algal species are ecophysiologically distinct (Škaloud \& Rindi 2013; Kamiya \& West 2014; Ryšánek et al. 2016), suggesting that these cryptic species may have specialized on the particular resource or habitat (niche) and this would allow them to coexist in sympatry.

Bostrychia intricata (Bory de Saint-Vincent) Montagne is a common intertidal red alga occurring in the Southern Hemisphere (Muangmai et al. 2014). This species has been studied from various biological aspects, including taxonomy, evolution, phylogeography, reproduction and physiology 
(Karsten et al. 1996; West et al. 1996; Zuccarello \& West 2008; Fraser et al. 2013; Muangmai et al. 2014, 2015a). Global phylogenetic diversity plus species delimitation analyses indicated eight cryptic species within this morphospecies, three of which are found in New Zealand (N2, N4 and N5) (Muangmai et al. 2014). Phylogeographic studies of New Zealand $B$. intricata indicated the coexistence of different cryptic species in some populations around Cook Strait (Muangmai et al. 2015a).

There are at least two possible explanations for the coexistence of sympatric cryptic species of Bostrychia intricata. First, different cryptic species occupy different intertidal habitats. Growth experiments of three sympatric cryptic species of $B$. intricata (N2, N4 and N5) from Moa Point (Cook Strait, North Island) previously indicated physiological differences among these cryptic species (Muangmai et al. 2015b). It is possible that the physiological differentiation seen in culture among $B$. intricata species could lead to the species inhabiting different ecological circumstances and allow the coexistence of these cryptic species. Another possibility for coexistence is the occurrence of vacant niche space filling on a 'first-come, first-served' basis (Sale 1982; Brokaw \& Busing 2000; Gillespie \& Roderick 2002). This concept emphasizes that the first species to arrive has a better chance to occupy the space and establish their population than later arrivals. It is a random process as to which species could fill the open ecological niches regardless of species-specific niche preferences (Silvertown \& Law 1987; Brokaw \& Busing 2000), and would lead to random distribution of species.

This study aims to determine the distribution pattern of coexisting cryptic algal species of Bostrychia intricata at small scales. We also test the hypothesis that the cryptic algal species can coexist in sympatry by occupying different intertidal habitats with respect to physical environmental factors. We surveyed the distribution of cryptic species of $B$. intricata in a population at Moa Point, Wellington with reference to physical factors: tidal position, wave and sun exposure. We first examined whether the coexistence of these cryptic species was random. Second, we wanted to determine which physical factors played a more significant role in promoting the microhabitat distribution pattern of cryptic $B$. intricata species.

\section{MATERIAL AND METHODS}

Samples of Bostrychia intricata were collected at Moa Point, Wellington $\left(41^{\circ} 20^{\prime} 40.78^{\prime \prime} \mathrm{S}, 174^{\circ} 48^{\prime} 35.34^{\prime \prime} \mathrm{E}\right)$ (Fig. $\mathrm{S} 1)$. Because of the patchy distribution of these species, we sampled one to two patches from each rock approximately every $2 \mathrm{~m}$. To test if patches were composed of single or multiple genets we sampled two to three ramets per patch. We recorded three physical factors from the middle of each patch: (1) tidal height, (2) sun exposure, and (3) wave exposure. To estimate the tidal level, we used a theodolite to measure the height of each algal patch above the sea surface calibrated to the predicted low tide for that day (Meteorological Service of New Zealand: http:// metservice.com/marine/tides/wellington). The degree of exposure to sun and waves was measured following Lewis (1964) and Schneider \& Helmuth (2007) with some modifications. We classified sun exposure on the basis of algal position: 'sun-protected' habitat if the algae was found in a rock crevice or on the underside of a rock; and 'sun-exposed' in other areas. We classified wave exposure on the basis of the direction the alga faced: 'wave-exposed' if the alga was facing the open coast and 'wave-protected' if the alga faced the shore. The classification of sun exposure and especially wave exposure is notoriously difficult (Airoldi \& Virgilio 1998; Knox 2001; Eckman et al. 2003).

All algal samples were placed in silica gel in the field. Algal specimens were identified on the basis of previous species descriptions (e.g. King \& Puttock 1989; Zuccarello \& West 2006, 2008). For DNA analyses, algal samples were rinsed in autoclaved seawater to remove any sand and dirt, and then the apical portions were used for DNA isolation.

Because of the large number of samples, we applied singlestrand conformational polymorphism (SSCP) analysis to screen the genetic variation within the population. DNA was isolated using a modified Chelex method (Zuccarello et al. 1999). The short fragment of mitochondrial cytochrome $\mathrm{c}$ oxidase subunit I gene (COI) ( $~ 200$ base pairs) was selected as an appropriate molecular marker for polymerase chain reaction (PCR) amplification (Muangmai et al. 2014, 2015a). PCR amplification was performed using primers (BiCOI_168F: GGAGCYGCRGTAGAYTTAGCRATTT and BiCOI_372R: TYGTAATTGCTCCRGCTAAAAC) designed from previous COI sequences (Muangmai et al. 2015a). The PCR reaction profile followed Fraser et al. (2013).

For SSCP analysis, we prepared a gel, $225 \mathrm{~mm}$ long and $0.75 \mathrm{~mm}$ thick (BioRad, Hercules, California, USA), by combining 20\% (37.5:1) acrylamide/bis-acrylamide solution (Sigma Aldrich, St Louis, Missouri, USA), 0.5× Trisborate-EDTA (TBE) buffer, $0.5 \%$ ammonium persulphate and $0.05 \%$ tetramethylethylenediamine (Biorad). Three microliters of PCR product were mixed with $9 \mu$ l of loading dye $(98 \%$ formamide, $0.025 \%$ bromophenol, $0.025 \%$ xylene cyanol and $10 \mathrm{mM} \mathrm{NaOH}$ ). Mixed PCR products were denatured at $95-100^{\circ} \mathrm{C}$ for 5 minutes and then snap cooled on ice before loading. Vertical acrylamide gel electrophoresis was run in $0.5 \times \mathrm{TBE}$ buffer at $12 \mathrm{~V}$ for $5-6$ hours at $4^{\circ} \mathrm{C}$. The gel was silver stained (Bassam et al. 1991) and banding patterns were analyzed by eye. In each gel, one or more samples with different or ambiguous SSCP banding profiles were sequenced. For sequencing, PCR products were purified using ExoSAP-IT (USB, Cleveland, Ohio, USA), and sequenced commercially (Macrogen Inc., Korea). Cryptic species and haplotype were defined on the basis of previous studies (Muangmai et al. 2014, 2015a).

The relationship between the distribution pattern of the cryptic species and the three physical factors was tested statistically. Factors were tested using IBM SPSS Statistics version 21 for Mac (IBM Corporation, Chicago, Illinois, USA). Three physical factors were initially defined as two different types of variables: (1) categorical variable for sun and wave exposure and (2) continuous variable for tidal height. For sun and wave exposure, the association between these two parameters and cryptic species distribution was analyzed by Pearson's chi-square test. Tidal height data were 
Table 1. Summary of Bostrychia intricata at Moa Point: cryptic species, COI haplotype, number of patches, percentage in wave and sun exposure area and tidal position range (above $0 \mathrm{~m}$ tidal height).

\begin{tabular}{|c|c|c|c|c|c|c|c|}
\hline \multirow{2}{*}{$\begin{array}{l}\text { Cryptic } \\
\text { species }\end{array}$} & \multirow{2}{*}{$\begin{array}{c}\text { COI } \\
\text { haplotype }\end{array}$} & \multirow{2}{*}{$\begin{array}{l}\text { Number } \\
\text { of patches }\end{array}$} & \multicolumn{2}{|c|}{ Wave exposure (\%) } & \multicolumn{2}{|c|}{ Sun exposure $(\%)$} & \multirow{2}{*}{$\begin{array}{l}\text { Tidal position } \\
\text { range }(\mathrm{m})\end{array}$} \\
\hline & & & Wave-exposed & Wave-protected & Sun-exposed & Sun-protected & \\
\hline N2 & $2 \mathrm{~A}$ & 55 & 76.3 & 23.7 & 72.7 & 27.3 & $1.15-1.75$ \\
\hline N2 & $2 \mathrm{~L}$ & 21 & 80.9 & 19.1 & 66.7 & 33.3 & $0.80-1.70$ \\
\hline N2 & $2 \mathrm{M}$ & 5 & 100.0 & 0 & 60.0 & 40.0 & $1.00-1.67$ \\
\hline N5 & $5 \mathrm{~A}$ & 13 & 46.1 & 53.9 & 61.5 & 39.5 & $1.30-1.60$ \\
\hline N4 & $4 \mathrm{E} 1$ & 18 & 33.3 & 66.7 & 50.0 & 50.0 & $1.50-3.40$ \\
\hline N4 & $4 \mathrm{E} 12$ & 14 & 21.4 & 78.6 & 57.0 & 53.0 & $1.65-3.00$ \\
\hline
\end{tabular}

initially tested for normality and homogeneity. Because of non-normal distribution of the data, the differences between the tidal heights of each cryptic species were tested using the Kruskal-Wallis nonparametric analysis of variance, following Dunn-Bonferroni post hoc tests. Additionally, discriminant function (DF) analysis was applied in determining which physical parameters influenced the distribution patterns of the cryptic species (McGarigal et al. 2000).

\section{RESULTS}

A total of 392 samples of Bostrychia intricata wase collected at Moa Point. On the basis of SSCP analysis and DNA sequences of these samples, three cryptic species were identified: N2, N4 and N5. Genetic analyses showed that only one COI haplotype was identified from each algal patch, indicating genetic homogeneity within a patch (patch is a genet), and therefore, we used only one genotype representing each patch for statistical analysis $(N=126)$. The

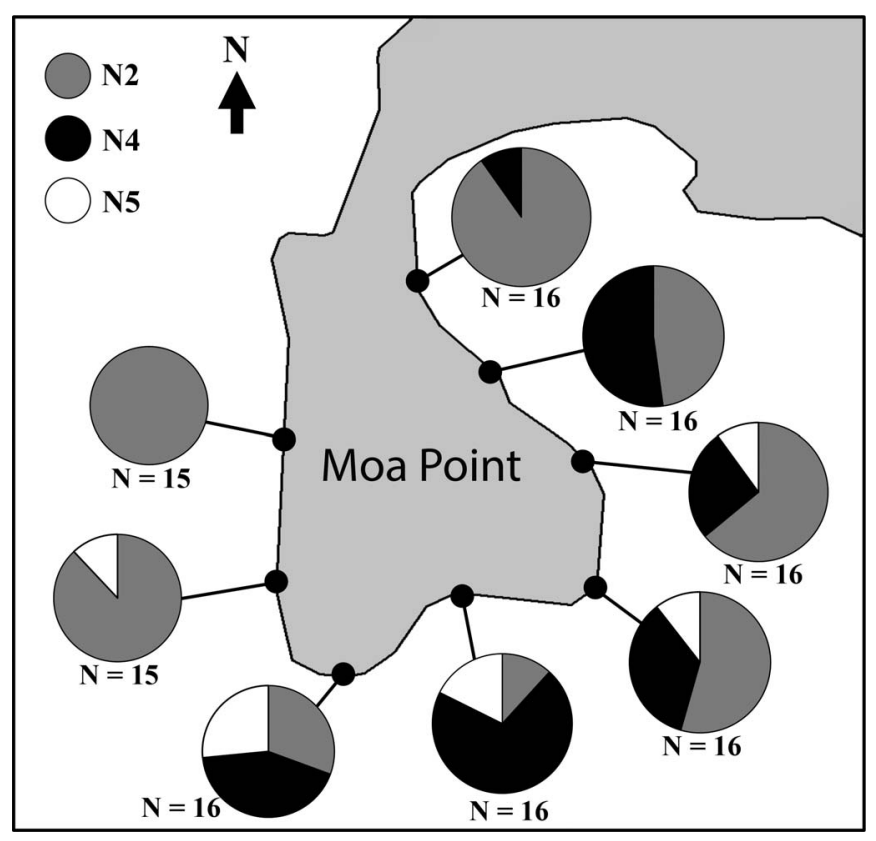

Fig. 1. Distribution of three cryptic species of Bostrychia intricata (N2, N4 and N5) around Moa Point, Wellington. Shading represents different cryptic species: grey, species N2; black, species N4 and white, species N5. Each pie chart represents the number $(\mathrm{N})$ of patches sampled on several rocks in the approximate area. occurrences of different cryptic species (distinct algal patch) on the same rock were occasionally observed. Cryptic species N2 was the most abundant species, accounting for approximately $64 \%$ of the total, followed by cryptic species N4 $(26 \%)$ and N5 (10\%). Higher genetic diversity was observed in cryptic species N2, with three haplotypes recognized (2A, $2 \mathrm{~L}$ and $2 \mathrm{M}$ ), whereas lower variation was found in cryptic species N4 with two (haplotypes 4E1 and 4E12) and N5 with one (haplotype 5A) (Table 1). Haplotypes $2 \mathrm{~L}$ and $2 \mathrm{M}$ of cryptic species N2 and haplotype 4E12 of cryptic species N4 were newly reported in this study (Genbank accession numbers KU882105-KU882107). Within cryptic species $\mathrm{N} 2$, haplotype $2 \mathrm{~A}$ was relatively common $(67 \%)$, compared with the other two haplotypes: $2 \mathrm{~L}(25 \%)$ and $2 \mathrm{M}(8 \%)$. The abundances of the two haplotypes of cryptic species N4 were only slightly different in this area $(56 \%$ for $4 \mathrm{E} 1$ and $54 \%$ for 4E12). Additionally, cryptic species N2 was widely distributed around Moa Point, but the other two cryptic species were restricted to the top and east side of the point (Fig. 1).

Pearson's chi-square tests showed a significant association between the distribution of cryptic Bostrychia intricata species and wave exposure, but not sun exposure. The occurrence of these cryptic species was significantly associated with wave exposure $\left(\chi^{2}=28.712, \mathrm{df}=5, P<0.0005\right)$. Cryptic species N2 was more frequently observed in waveexposed areas than the other species $(>70 \%$ for all haplotypes), whereas cryptic species N4 was more likely to be found in wave-protected areas $(\sim 70 \%$ for both haplotypes) (Table 1). On the other hand, the distribution of cryptic species was not significantly related to sun exposure $\left(\chi^{2}=3.756, \mathrm{df}=5, P=0.585\right)$. Cryptic species N2 (haplotype $2 \mathrm{M}), \mathrm{N} 4$ and N5 were likely to be symmetrically dispersed in either sun-exposed or sun-protected areas (Table 1). For tidal position, the Dunn-Bonferroni post hoc tests indicated significant differences in average mean tidal heights among these cryptic species $(P<0.05)$ (Fig. 2). Cryptic species N4 was distributed at a higher tidal position, ranging from 1.5 to $3.4 \mathrm{~m}$., than the other two species: N2 $(0.8$ to $1.75 \mathrm{~m}$.) and N5 (1.3 to $1.6 \mathrm{~m}$.) (Table 1$)$.

Discriminant analysis (Wilk's lambda test) indicated a significant difference in the distribution of cryptic Bostrychia intricata species $(P<0.05$ in all functions, Table $\mathrm{S} 1)$. In this analysis, the first two DFs accounted for $99.5 \%$ of variance between groups (DF1 90.8\% and DF2 8.7\%). The twodimension plot (DF1 and DF2) of the discriminant analysis of three physical factors clearly showed differentiation between cryptic species (Fig. 3). Cryptic species N4 was clearly separated from the other two species, whereas species 


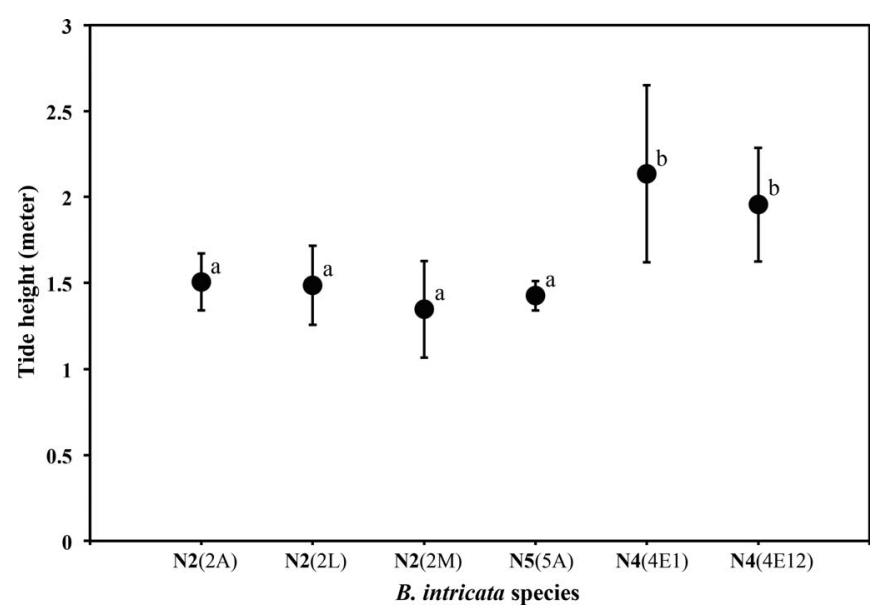

Fig. 2. Average mean tidal heights $( \pm \mathrm{SE})$ above $0 \mathrm{~m}$ tidal height of each cryptic Bostrychia intricata species (all haplotypes) found at Moa Point. The letters indicate significant difference $(P<0.05)$. The number of patches in each haplotype shows in Table 1.

N2 was intermingled with N5 (Fig. 3). Within-group correlations between the three physical parameters and DFs, tidal position contributed dominantly to DF1, whereas wave exposure contributed more than other factors to DF2 (Table S2). This analysis implies that tidal position most strongly influenced the distribution pattern of these cryptic species, followed by wave exposure.

\section{DISCUSSION}

Our intensive survey, based on the collection of nearly 400 samples, clearly shows that cryptic Bostrychia intricata species N2, N4 and N5 grow sympatrically, even on the same rock, along a shoreline of approximately $700 \mathrm{~m}$ at Moa Point. This indicates high levels of cryptic species diversity at a microgeographic scale. Three additional haplotypes for cryptic species N2 and N4 were also observed in this study. At similar small-area levels within New Zealand, similar patterns of high species-level diversity was observed in the red alga, Pyropia, at Brighton Beach from the South Island (as Porphyra, Schweikert et al. 2012). Many studies on phylogenetic diversity and biogeography have demonstrated the sympatric occurrence of different cryptic algal species within a confined space, especially in red algae, for example Bostrychia radicans (Montagne) Montagne/B. moritziana (Sonder ex Kützing) J.Agardh (Zuccarello \& West 2003), Portieria hornemannii (Lyngbye) P.C.Silva (Payo et al. 2013) and Pyropia yezoensis (Ueda) M.S.Hwang \& H.G.Choi (Niwa et al. 2014). As a result, we emphasize the importance

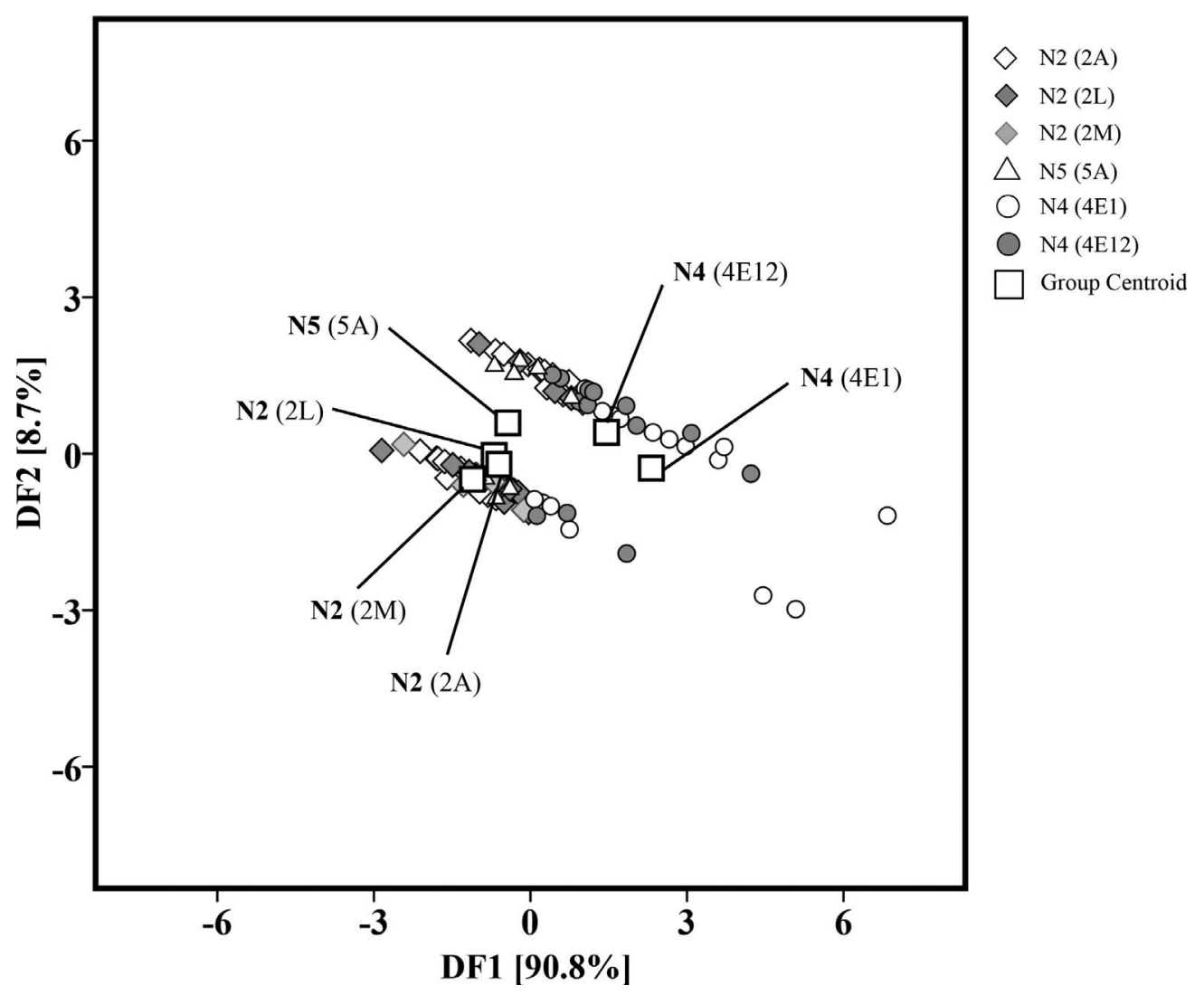

Fig. 3. Discriminant analysis plot for three physical parameters (tidal height, wave exposure and sun exposure) of each cryptic Bostrychia intricata species (all haplotypes) collected from Moa Point. Shape and shading represent haplotypes of $B$. intricata: white rhombus, haplotype 2A (N2); dark grey rhombus, haplotype 2L (N2); light grey rhombus, haplotype 2M (N2); white triangle, haplotype 5A (N5); white circle, haplotype 4E1 (N4); grey circle, haplotype 4E12 (N4) and white square, group centroid of each haplotype. The number of patches in each haplotype shows in Table 1. 
of small spatial-scale studies, incorporating intensive sampling, to provide more detail about the diversity pattern and abundance of cryptic algal species at all scales.

Our data also suggested that each patch of Bostrychia intricata was made up of only one genet. A previous study of clonal diversity of the marine green alga Cladophoropsis membranacea (Hofman Bang ex C.Agardh) Børgesen, based on microsatellite analyses, showed the differences of genetic composition within a patch (Van der Strate et al. 2002). For example, patches of approximately $1-10 \mathrm{~cm}$ in diameter consisted of single genotypes, whereas larger patches $(>50$ $\mathrm{cm}$ in diameter) contained multiple genotypes (Van der Strate et al. 2002). It is possible that the homogeneity detected within $B$. intricata patches could probably be due to the use of a less variable genetic marker. We suggest that further study with more variable markers (e.g. microsatellites or single-nucleotide polymorphisms) may help to determine whether the patches are composed of multiple genets.

Our data indicate that cryptic species are not distributed randomly but that there is substantial difference in smallscale distribution between the cryptic Bostrychia intricata species at Moa Point, and it is likely strongly influenced by, and possibly due to, the interaction of tide height and wave exposure (Fig. 3 and Table S2). Very few studies have reported ecological differences between cryptic algal species. For example, different lineages of the green alga Klebsormidium flaccidum (Kützing) P.C. Silva, Mattox \& Blackwell could be found in different habitats (water, artificial substrate or natural substrate) (Škaloud \& Rindi 2013). Although ecophysiological differences between cryptic algal species were previously observed (Škaloud \& Rindi 2013; Kamiya \& West 2014), our quantitative study is the first to show habitat partitioning among sympatric cryptic algal species in the field.

In intertidal communities, tidal height plays a significant role in shaping the population structure and distribution pattern of sessile marine organisms, including macroalgae (Underwood \& Jernakoff 1984; Harley \& Helmuth 2003; Hurd et al. 2014). We found that the distributions of three cryptic species of Bostrychia intricata were patterned, mostly segregating between high and middle-low intertidal shores. Several studies have focused on the vertical distribution along the intertidal of different, or within, algal species. Two closely related brown algae of the genus Fucus, $F$. vesiculosus Linnaeus and $F$. spiralis Linnaeus, inhabited different tidal positions on the coastline of France and Portugal (Zardi et al. 2011). In the red alga Chondrus crispus Stackhouse, genetic differentiation was found between high and low shore populations (Krueger-Hadfield et al. 2013).

Few studies have shown a clear correlation between physiological properties of algal species and distribution pattern in facilitating zonation. Intertidal ecological studies have shown that the high intertidal zone is an extreme environment (e.g. high temperature, increased salinity, long period of desiccation), and only a few well-adaptive algal taxa maintain their populations in this area (Zardi et al. 2011, Hurd et al. 2014). The upper-shore Fucus spiralis had more desiccation tolerance than lower-shore $F$. vesiculosus (Zardi et al. 2011). Additionally, the physiological performance of different genotypes of the red alga Caloglossa vieillardii (Kützing) Setchell [as C. leprieuri (Montagne)
J.Agardh] was correlated with their abundance and was suggested to be a reason for these differences in abundance in a population in eastern Australia (Zuccarello et al. 2001). We found that cryptic species N4 was normally found high on the shore, close to the upper limit of any alga in this area (personal observations), whereas the other two species, N2 and N5, occur lower in the littoral zone. Laboratory experiments clearly showed that when comparing the specific growth rate of the three cryptic Bostrychia intricata species with various salinities and temperatures, cryptic species N4 grew more rapidly than N2 and N5 in the conditions tested (Muangmai et al. 2015a). The ability of cryptic species N4 to grow well in a broader range of salinity and temperatures could explain its occupation of the upper intertidal shore.

In addition, the less abundant cryptic species N5 (10\% of the total) correlated well with its lower performance in physiological tolerance experiments compared with the other cryptic species (Muangmai et al. 2015a). These results confirm that differences in the pattern of vertical distribution and abundance between cryptic algal species could be due to physiological differences and are adaptations that allow coexistence in the same location.

Different levels of wave exposure also influence the occurrence of intertidal macroalgal species (Scrosati \& Mudge 2004; Hurd et al. 2014). For example, in the Canary Islands, the brown alga Dictyota cymatophila Tronholm, M.Sansón \& Afonso-Carrillo more frequently occurred in wave-exposed habitats, whereas D. dichotoma (Hudson) J.V.Lamouroux was found in less-exposed areas (Tronholm et al. 2010). Additionally, physical conditions related to wave exposure limit the horizontal distribution of marine macroalgae, as found in the intertidal kelp Postelsia palmaeformis Ruprecht from the northeast Pacific (Nielsen et al. 2006). Our study, although providing a simple measure of wave exposure, suggests different spatial distribution of three cryptic Bostrychia intricata species with respect to wave exposure.

Our findings provide evidence of ecological habitat separation between cryptic Bostrychia intricata species, indicating a nonrandom pattern in small-scale distribution of these cryptic species, which can account for their coexistence. However, these results were evident only for the differences between cryptic species N4 and other species, but are still equivocal between cryptic species N2 and N5. If distinct intertidal habitats exist between cryptic species N2 and N5, this could probably be related to other nonmeasured differences, e.g. mating period or seasonal abundance, as found in sibling species of Dictyota (Tronholm et al. 2010). Further studies of sympatric cryptic species of $B$. intricata should consider other factors, e.g. temporal distribution, reproductive timing and abundance of different life phases that could contribute toward the comprehensive understanding of how cryptic algal species coexist at small scales.

\section{ACKNOWLEDGEMENTS}

We thank John van der Sman and Christian Boedeker for valuable suggestions in experimental design and Maren 
Preuss for sampling help. We also thank Dalice Sim and Cong Zeng for statistical suggestions. Special thanks to Victoria University of Wellington for providing a scholarship to NM.

\section{SUPPLEMENTARY DATA}

Supplementary data associated with this article can be found online at http://dx.doi.org/10.2216/16-5.1.s1.

\section{REFERENCES}

Airoldi L. \& Virgilio M. 1998. Responses of turf-forming algae to spatial variations in the deposition of sediments. Marine Ecology Progress Series 165: 271-282.

Bassam B.J., Caetano-Anollés G. \& Gresshoff P.M. 1991. Fast and sensitive silver staining of DNA in polyacrylamide gels. Analytical Biochemistry 196: 80-83.

Benzie J.A.H., Ballment E. \& Edyvane K. 2000. Allozymes as genetic identification markers of Sargassum spp. (Phaeophyta) from the Great Barrier Reef, Australia. Botanica Marina 43: 169179 .

Bickford D., Lohman D.J., Sodhi N.S., Ng P.K.L., Meier R., Winker K., Ingram K.K. \& Das I. 2007. Cryptic species as a window on diversity and conservation. Trends in Ecology \& Evolution 22: 148-155.

Brokaw N. \& Busing R.T. 2000. Niche versus chance and tree diversity in forest gaps. Trends in Ecology \& Evolution 15: 183-88.

De Troch M., Fiers F. \& VincX M. 2003. Niche segregation and habitat specialisation of harpacticoid copepods in a tropical seagrass bed. Marine Biology 142: 345-355.

Eckman, J. E., Duggins, D. O. \& Siddon, C. E. 2003. Current and wave dynamics in the shallow subtidal: implications to the ecology of understory and surface-canopy kelps. Marine Ecology Progress Series 265: 45-56.

Fraser C.I, Zuccarello G.C., Spencer H.G., Salvatore L.C., Garcia G.R. \& Waters J.M. 2013. Genetic affinities between trans-oceanic of non-buoyant macroalgae in the high latitudes of the Southern Hemisphere. PLOS One 8: e69138.

GAusE G.F. 1934. The struggle for existence. Williams and Wilkins, Baltimore. $192 \mathrm{pp}$.

Gillespie R.G. \& Roderick G.K. 2002. Arthropods on islands: colonization, speciation and conservation. Annual Review of Entomology 47: 595-632.

Harley C.D.G. \& Helmuth B.S.T. 2003. Local and regional-scale effects of wave exposure, thermal stress, and absolute versus effective shore level on patterns of intertidal zonation. Limnology and Oceanography 48: 1498-1508.

Hurd C.L., Harrison P.J., Bischof K. \& Lobban C.S. 2014. Seaweed ecology and physiology, ed. 2. Cambridge University Press, Cambridge, UK. 551 pp.

Kamiya M. \& West J.A. 2014. Cryptic diversity in the euryhaline red alga Caloglossa ogasawaraensis (Delesseriaceae, Ceramiales). Phycologia 53: 374-82.

Kamiya M., West J.A., King R.J., Zuccarello G.C., Tanaka J. \& HARA Y. 1998. Evolutionary divergence in the red algae Caloglossa leprieurii and C. apomeiotica. Journal of Phycology 34: 361-370.

Karsten U., Кoch S., West J.A. \& Kirst G.O. 1996. Physiological responses of the eulittoral macroalga Stictosiphonia hookeri (Rhodomelaceae, Rhodophyta) from Argentina and Chile: salinity, light and temperature acclimation. European Journal of Phycology 31: 361-368.

King R.J. \& PutTock C.F. 1989. Morphology and taxonomy of Bostrychia and Stictosiphonia (Rhodomelaceae/Rhodophyta). Australian Systematic Botany 2: 1-73.

Knowlton, N. 2000. Molecular genetic analyses of species boundaries in the sea. Hydrobiologia 420: 73-90.
Knox G.A. 2001. The ecology of seashores. CRC Press, Boca Raton, Florida. $557 \mathrm{pp}$.

Krueger-Hadfield S.A., Roze D., Mauger S. \& Valero M. 2013. Inter-gametophytic selfing and microgeographic genetic structure shape populations of the intertidal red seaweed Chondrus crispus. Molecular Ecology 22: 3242-3260.

Lai C.H., Morley S.A., Tan K.S. \& PeCK L.S. 2011. Thermal niche separation in two sympatric tropical intertidal Laternula (Bivalvia: Anomalodesmata). Journal of Experimental Marine Biology and Ecology 405: 68-72.

LANKAU R.A. 2011. Rapid evolutionary change and the coexistence of species. Annual Review of Ecology, Evolution and Systematics 42: $335-354$.

LEVINTON J.S. 2013. Marine biology: function, biodiversity, ecology, ed. 4. Oxford University Press, New York. 576 pp.

LEWIS J.R. 1964. The ecology of rocky shores. English Universities Press, London. 323 pp.

LindSTROM S.C. 2008. Cryptic diversity and phylogenetic relationships within the Mastocarpus papillatus species complex (Rhodophyta, Phyllophoraceae). Journal of Phycology 44: 1300-1308.

McCourt R.M. 1984. Niche differences between sympatric Sargassum species in the northern Gulf of California. Marine Ecology Progress Series 18: 139-148.

McGarigal K., Cushman S.A. \& Stafford S.G. 2000. Multivariate statistics for wildlife and ecology research. Springer-Verlag, New York. 283 pp.

Muangmai N., West J.A. \& Zuccarello G.C. 2014. Evolution of four Southern Hemisphere Bostrychia (Rhodomelaceae, Rhodophyta) species: phylogeny, species delimitation and divergence times. Phycologia 53: 593-601.

Muangmai N., Fraser C.I. \& Zuccarello G.C. 2015a. Contrasting patterns of population structure and demographic history in cryptic species of Bostrychia intricata (Rhodomelaceae, Rhodophyta) from New Zealand. Journal of Phycology 51: 574-585.

Muangmai N., Preuss M. \& Zuccarello G.C. 2015b. Comparative physiological studies on the growth of cryptic species of Bostrychia intricate (Rhodomelaceae, Rhodophyta) in various salinity and temperature conditions. Phycological Research 63: 300-306.

Nielsen K.J., Blanchette C.A., Menge B.A. \& Lubchenco J. 2006. Physiological snapshots reflect ecological performance of the sea palm, Postelsia palmaeformis (Phaeophyceae), across intertidal elevation and exposure gradients. Journal of Phycology 42: 548559

Niwa K., Kikuchi N., Hwang M.S., Choi H.G. \& Aruga Y. 2014. Cryptic species in the Pyropia yezoensis complex (Bangiales, Rhodophyta): sympatric occurrence of two cryptic species even on same rocks. Phycological Research 62: 36-43.

Odum E.P. 1959. Fundamentals of ecology, ed. 2. W. B. Saunders Co., Philadelphia. 546 pp.

Payo D.A., Leliaert F., Verbruggen H., D'Hondt S., Calumpong H. P. \& De Clerck O. 2013. Extensive cryptic species diversity and fine scale-scale endemism in the marine red alga Portieria in the Philippines. Proceeding of Royal Society B: Biological Science 280: 2012-2660.

Ryšánek D., Holzinger A. \& Skaloud P. 2016. Influence of substrate and $\mathrm{pH}$ on the diversity of aeroterrestrial alga Klebsormidium (Klebsormidiales, Streptophyta): a potentially important factor for sympatric speciation. Phycologia 55: 347358.

SALE P.F. 1982. Stock-recruit relationships and regional coexistence in a lottery competitive system: a simulation study. American Naturalist 120: 139-159.

Sampoya E. M., Franceschinis L., Hoegh-Guldberg O. \& Dove S. 2007. Niche partitioning of closely related symbiotic dinoflagellates. Molecular Ecology 16: 3721-3733.

Schneider K.R. \& Helmuth B. 2007. Spatial variability in habitat temperature may drive patterns of selection between an invasive and native mussel species. Marine Ecology Progress Series 339: $157-167$.

Schweikert K., Sutherland J.E., Burritt D.J. \& Hurd C.L. 2012. Analysis of spatial and temporal diversity and distribution of Porphyra (Rhodophyta) in southeastern New Zealand supported by the use of molecular tools. Journal Phycology 48: 530-538. 
Scrosati R. \& Mudge B. 2004. Effects of elevation, wave exposure, and year on the proportion of gametophytes and tetrasporophytes in Mazzaella parksii (Rhodophyta, Gigartinaceae) populations. Hydrobiologia 520:199-205.

Silvertown J. 2004. Plant coexistence and the niche. Trends in Ecology \& Evolution 19: 605-611.

Silvertown J. \& Law R. 1987. Do plants need niches? Some recent developments in plant community ecology. Trends in Ecology \& Evolution 2: 24-26.

ŠKaloud P. \& Rindi F. 2013. Ecological differentiation of cryptic species within an asexual protist morphospecies: a case study of filamentous green alga Klebsormidium (Streptophyta). Journal of Eukaryotic Microbiology 60: 350-362.

TOKeshi M. 1999. Species coexistence: ecological and evolutionary perspectives. Blackwell Science, Oxford, UK. 454 pp.

Tronholm A., Sanson M., Afonso-Carillo J., Verbruggen H. \& De Clerck O. 2010. Niche partitioning and the coexistence of two cryptic Dictyota (Dictyotales, Phaeophyceae) species from the Canary Islands. Journal of Phycology 46: 1075-1087.

Underwood A.J. \& JeRnAKofF P. 1984. The effects of tidal height, wave-exposure, seasonality and rock-pools on grazing and the distribution of intertidal macroalgae in New South Wales. Journal of Experimental Marine Biology and Ecology 75: 71-96.

Van Der Strate H.J., Van De Zande L., Stam W.T. \& Olsen J.L. 2002. The contribution of haploids, diploids and clones to finescale population structure in the seaweed Cladophoropsis membranacea (Chlorophyta). Molecular Ecology 11: 329-345.

West J.A., Zuccarello G.C. \& Karsten U. 1996. Reproductive biology of Stictosiphonia hookeri (Rhodomelaceae, Rhodophyta) from Argentina, Chile, South Africa and Australia in laboratory culture. Hydrobiologia 326/327: 277-282.

Zardi G.I., Nicastro K.R., Canovas F., Costa J.F., Serrão E.A \& Pearson G.A. 2011. Adaptive traits are maintained on steep selective gradients despite flow and hybridization in the intertidal zone. PLOS One 6: e19402.

Zhang D.Y., Lin K. \& HansKi I. 2004. Coexistence of cryptic species. Ecology Letters 7: 165-169.

Zuccarello G.C. \& West J.A. 2003. Multiple cryptic species; molecular diversity and reproductive isolation in Bostrychia radicans/B. moritziana complex (Rhodomelaceae, Rhodophyta) with focus on North American isolates. Journal of Phycology 39: 948-959.

Zuccarello G.C. \& West J.A. 2006. Molecular phylogeny of the subfamily Bostrychioideae (Ceramiales, Rhodophyta): subsuming Stictosiphonia and highlighting polyphyly in species of Bostrychia. Phycologia 45: 24-36.

Zuccarello G.C. \& West J.A. 2008. Bostrychia (Rhodomelaceae, Rhodophyta) species of New Zealand, and relationships in Southern Hemisphere. New Zealand Journal of Marine and Freshwater Research 42: 315-324.

Zuccarello G.C., West J.A. \& King R.J. 1999. Evolutionary divergence in Bostrychia moritziana/B. radicans complex (Rhodomelaceae, Rhodophyta): molecular and hybridization data. Phycologia 38: 234-244.

Zuccarello G.C., Yeates P.H., Wright J.T. \& Bartlett J. 2001 Population structure and physiological differentiation of haplotypes of Caloglossa leprieurii (Rhodophyta) in a mangrove intertidal zone. Journal of Phycology 37: 235-244.

Zuccarello G.C., Sandercock B. \& West J.A. 2002. Diversity within red algal species: variation in world-wide samples of Spyridia filamentosa (Ceramiaceae) and Murrayella periclados (Rhodomelaceae) using DNA markers and breeding studies. European Journal of Phycology 37: 403-418.

Received 8 January 2016; accepted 22 March 2016 